Hal. $283-296$

\title{
PENGARUH KUALITAS PRODUK DAN KUALITAS LAYANAN TERHADAP KEPUASAN DAN LOYALITAS PENGGUNA KASMDI KBS
}

\author{
Galih Arief Prakosa \\ Magister Manajemen Teknologi, Institut Teknologi Sepuluh November \\ Surabaya \\ arief.prakosa59@gmail.com \\ Udisubakti Ciptomulyono \\ Magister Manajemen Teknologi, Institut Teknologi Sepuluh \\ NovemberSurabaya \\ udisubakti@gmail.com \\ Fuad Achmadi \\ Magister Manajemen Teknologi, Institut Teknologi Sepuluh November \\ Surabaya \\ fuadachmadi@gmail.com
}

\begin{abstract}
The availability of consumable water is a basic human right. The State Water Supply Company (PDAM) Surya Sembada is the only government institution in charge in providing and managing drinking water facilities and infrastructure in Surabaya. PDAM Surya Sembada provides free fountain drinking (KASM) as their Corporate Social Responsibility (CSR) program that located in various strategic public places in the city including in Surabaya Zoo (KBS). However, there has never been any analysis on the product and service quality of the KASM in KBS. Therefore, the objective of this study is to analyze the effect of product and service quality of the KASM in KBS on user satisfaction and loyalty using Structural Equation Modeling (SEM) with Partial Least Square (PLS) analysis. Results of path coefficient analysis show that product quality affects user satisfaction, but it has no effect on user loyalty. Service quality affects user satisfaction and loyalty. User satisfaction affects user loyalty. It can be concluded that user satisfaction is affected by product and service quality, while user loyalty is affected by service quality and user satisfaction.
\end{abstract}

Keywords: KASM, Product Quality, Service Quality, User Satisfaction, User Loyalty.

Abstrak: Ketersediaan air layak konsumsi merupakan hak asasi manusia. Perusahaan Daerah Air Minum (PDAM) Surya Sembada adalah satu-satunya institusi pemerintah yang bertugas menyediakan dan mengelola sarana dan prasarana air minum di Kota Surabaya. Dalam upaya memenuhi tanggung jawabnya, PDAM Surya Sembada menyediakan Kran Air Siap Minum (KASM) berupa fasilitas air minum gratis sebagai program CSR yang berlokasi diberbagai ruang publik strategis di wilayah kota, termasuk di Kebun Binatang Surabaya (KBS). Namun, sampai saat ini belum pernah dilakukan upaya untuk menganalisis kualitas produk dan layanan dari fasilitas tersebut. Penelitian ini bertujuan untuk menganalisis pengaruh kualitas produk dan kualitas layanan terhadap kepuasan dan loyalitas pengguna KASM di KBS dengan menggunakan metode SEM-PLS. Analisis path coefficient 
menunjukkanbahwa kualitas produk berpengaruh terhadap kepuasan pengguna, namun tidak berpengaruh langsung terhadap loyalitas pengguna. Kualitas layanan berpengaruh terhadap kepuasan pengguna dan berpengaruh langsung terhadap loyalitas pengguna.Kepuasan pengguna berpengaruh langsung terhadap loyalitas pengguna. Simpulan penelitian ini adalah kepuasan pengguna dipengaruhi oleh kualitas produk dan kualitas layanan, sedangkan loyalitas pengguna dipengaruhi langsung oleh kualitas layanan dan kepuasan pengguna.

Kata Kunci: KASM, Kualitas Produk, Kualitas Layanan, Kepuasan Pengguna, Loyalitas Pengguna.

\section{Pendahuluan}

Kebutuhan air bersih dan air minum manusia, akan terus meningkat seiring bertambahnya populasi, terutama di daerah perkotaan akibat makin terbatasnya sumber air yang layak konsumsi. Ketersedian air bersih sudah menjadi hak asasi dasar manusia, sebagaimana dinyatakan dalam piagam PBB (universal declaration of human right). Air minum harus memiliki karakteristik utama: tidak berwarna, tidak berbau, dan tidak berasa, serta memiliki kondisi bersih (jernih), tidak mengandung bahan tersuspensi atau kekeruhan (turbidity). Standar untuk air minum telah ditentukan secara Internasional oleh WHO (Wiriya, 1996).

Perusahaan Daerah Air Minum (PDAM) menurut UU No 5 tahun 1962, adalah suatu kesatuan usaha milik pemerintah daerah yang memberikan jasa pelayanan dan menyelenggarakan kemanfaatan umum dibidang air minum. Kran Air Siap Minum (KASM) merupakan program unggulan dari beberapa PDAM, termasuk PDAM Surya Sembada Kota Surabaya, sebagai bentuk kepedulian, tanggung jawab sosial perusahaan/ korporasi (corporate social responsibility) bagi masyarakat dan lingkungan. Kehadiran KASM sekaligus menambah produk layanan air PDAM, dari sebelumnya hanya air bersih/ minum berbayar, kini tersedia pula layanan air minum gratis berkualitas bagi masyarakat. Sejak tahun 2009 hingga tahun 2015, PDAM Surya Sembada telah menyediakan 19 titik KASM yang tersebar di 18 lokasi di wilayah kota Surabaya. Kebun Binatang Surabaya (KBS) merupakan satu-satunya ruang publik di kota Surabaya yang mendapat alokasi KASM sebanyak 2 unit, mengingat area kawasannya yang cukup luas dan potensi penggunanya yang besar. Layanan yang diresmikan sejak tahun 2014 ini, bertujuan agar para pengunjung tidak perlu membawa air kemasan dalam jumlah banyak, sekaligus edukasi dalam mengurangi volume limbah kemasan air minum (Dinkominfo, 2014).

Evaluasi pemanfaatan KASM hingga saat ini baru dilakukan pihak PDAM sebatas jika terjadi masalah operasi. Berdasarkan data-data operasi dan perawatan untuk KASM KBS selama tahun 2015, diketahui bahwa penyerapan anggaran untuk bea penggantian spare part mencapai $68 \%$, atau ada selisih (gap) 32\% lebih rendah dari target anggaran yang direncanakan. Idealnya, penyerapan bea penggantian spare parts tersebut harus 
mendekati $100 \%$ anggarannya. Adanya gap ini menjadi indikasi sederhana bahwa penggunaan KASM masih di bawah kapasitas terpasangnya. Sehingga dapat dikatakan, harapan PDAM agar KASM dapat menjadi alternatif yang diminati pengunjung KBS dalam memenuhi kebutuhan dasar air minumnya, belum mencapai kesuksesan.

Kesuksesan perusahaan dalam mencapai tujuan utama adalah adanya keberhasilan memenuhi dan memuaskan kebutuhan, keinginan pelanggan/ pengguna produknya. Produk bisa dalam bentuk barang/jasa/keduanya, adalah segala sesuatu yang dapat ditawarkan ke pasar untuk memuaskan keinginan dan kebutuhan. Kualitas layanan adalah hasil persepsi yang ditimbulkan setelah pelanggan/ pengguna membandingkan antara kualitas yang diterima dengan harapannya. Kualitas layanan biasanya dapat diukur dengan suatu model yang populer disebut SERVQUAL, yang ditentukan berdasarkan 5 (lima) dimensi yaitu; tangible, reliability, responsivenes, assurance, dan emphaty (Parasuraman A. Z., 1985). Namun model ini ternyata juga memiliki keterbatasan yaitu: (1) tidak dapat meninjau langsung hubungan pengaruh variabel yang lebih kompleks (multivariate); (2) tidak meninjau kualitas produk (barang), sehingga murni hanya layanan (Meirovich and Bahnan, 2008). Kualitas produk yang ditentukan berdasarkan 8 (delapan) dimensi yaitu: performance, features, reliability, conformance, durability, serviceability, aesthetics, dan perceived quality (Garvin, 1987), dihadirkan guna melengkapi analisa pengaruh kualitas layanan terhadap kepuasan pelanggan/ pengguna.

Kepuasan pelanggan (customer satisfaction) merupakan salah satu faktor penentu keberhasilan persepsi perusahaan, dan dapat memberikan manfaat terciptanya hubungan yang baik antara perusahaan dan para pelanggannya. Keadaan ini berpeluang terjadinya pembelian/ penggunaan kembali, serta berpotensi mendorong para pelanggan/ pengguna tersebut dapat merekomendasikan/ mempromosikan pelayanan dan produk perusahaan. Keberhasilan perusahaan untuk menjalin relationship yang baik dengan pelanggan/ penggunanya tersebut adalah fondasi untuk membentuk loyalitas yang kuat (Zeithaml and Bitner, 1996).

Keberhasilan PDAM Surya Sembada Kota Surabaya dalam memberikan kualitas produk dan kualitas layanan KASM, tentu akan mempengaruhi tingkat kepuasan bagi penggunanya. Adanya kepuasan tersebut, diharapkan mampu menumbuhkan loyalitas pengguna untuk selalu memanfaatkan KASM dalam memenuhi kebutuhan air minum saat berada di ruang publik seperti KBS. Oleh sebab itu perlu dilakukan evaluasi KASM melalui persepsi pengguna, berdasarkan kondisi kualitas produk dan kualitas layanan saat ini, agar dapat diketahui bagaimana pengaruhnya terhadap tingkat kepuasan dan loyalitas penggunanya.

Kualitas produk adalah kemampuan dari suatu produk yang dapat memberikan segalanya lebih besar atau lebih unggul sebagai pembanding dengan alternatif bersaing 
dari pandangan pasar (Garvin, 1987). Kualitas suatu produk baik berupa barang atau jasa ditentukan melalui dimensi-dimensinya, yang menurut Garvin (1987) disebut sebagai 8 dimensi kualitas produk (Tjiptono and Chandra, 2008) sbb:

1. Kinerja (performance)

Karakteristik kemampuan operasi dasar atau utama dari sebuah produk.

2. Fitur (features)

Karakteristik sebagai pendukung atau pelengkap produk (sekunder), yang dirancang untuk menyempurnakan fungsi dasar produk (primer) atau menambah ketertarikan konsumen/ pengguna terhadap produk.

3. Kesesuaian (conformance)

Karakteristik kesesuaian kinerja operasi dasar dan kualitas produk, dalam memenuhi standar/ kriteria/ spesifikasi tertentu yang diinginkan konsumen/ pengguna.

4. Kehandalan (reliability)

Probabilitas bahwa produk dapat bekerja dengan memuaskan atau sebaliknya, dalam periode waktu dan kondisi tertentu.

5. Daya tahan (durability)

Kemampuan produk untuk bertahan lama saat digunakan, sebelum harus diganti, yang diukur berdasarkan umur dan waktu pakai.

6. Kemudahan (service ability)

Karakteristik yang meliputi kecepatan dan kemudahan layanan dalam proses perbaikan. (identik dengan purna jual).

7. Estetika (aesthetics)

Karakteristik yang berhubungan dengan panca indera.

8. Kesan kualitas (perceived quality)

Karakteristik yang berhubungan dengan kesan/ persepsi yang dirasakan konsumen/ pengguna atas produk maupun merk yang bersangkutan.

Kualitas layanan merupakan evaluasi keseluruhan dari fungsi jasa yang diterima secara aktual oleh pelanggan (kualitas teknis), dan bagaimana cara layanan tersebut disampaikan (kualitas fungsional). Dimensi persepsi kualitas layanan menurut Parasuraman, et.al (1994) sbb:

1. Bukti fisik (tangible)

Kemampuan suatu perusahaan/ institusi/ manajemen dalam menunjukkan eksistensinya kepada pihak eksternal.

2. Kehandalan (reliability)

Kemampuan perusahaan/ institusi/ manajemen untuk memberikan pelayanan sesuai yang dijanjikan secara akurat dan terpercaya. 


\section{Ketanggapan (responsiveness)}

Kemauan untuk membantu dan memberikan pelayanan yang cepat dan tepat kepada pelanggan dengan penyampaian informasi yang jelas.

4. Jaminan dan kepastian (assurance)

Pengetahuan, kesopansantunan, dan kemampuan para karyawan perusahaan untuk menumbuhkan rasa percaya para pelanggan kepada perusahaan.

5. Empati (emphaty)

Memberikan perhatian yang tulus dan bersifat individual atau pribadi yang diberikan kepada para pelanggan dengan berupaya memahami keinginan pelanggan.

Kepuasan pelanggan adalah keseluruhan sikap yang ditunjukkan konsumen atas barang atau jasa setelah mereka memperoleh dan menggunakannya (Mowen and Minor, 2002), dengan dimensi sbb:

1. Berhubungan dengan atribut produk (attributes related to product)

Kemampuan produk dan konsistensinya yakni kemampuan dari produk sesuai dengan yang dijanjikan oleh perusahaan.

2. Berhubungan dengan atribut pelayanan (attributes related to service).

Garansi produk yakni garansi yang diberikan sesuai dengan pelayanan purna jual yang telah dijanjikan.

3. Berhubungan dengan atribut pengadaan (attributes related to purchase).

Reputasi perusahaan yakni reputasi yang dimiliki oleh perusahaan.

Loyalitas adalah sebuah komitmen yang dipegang teguh untuk membeli kembali atau re-patronize produk atau jasa yang lebih disukai di masa yang akan datang meskipun pengaruh situasional dan upaya pemasaran memiliki potensi untuk menyebabkan perilaku berubah (Kotler and Keller, 2010). Tujuan akhir keberhasilan perusahaan menjalin relationship dengan pelanggannya adalah untuk membentuk loyalitas yang kuat. Dimensi dari loyalitas yang kuat (Zeithaml and Bitner, 1996) adalah sebagai berikut :

1. Say positive things

Mengatakan hal yang positif tentang produk yang dikonsumsi.

\section{Recommend friend}

Merekomendasikan produk yang telah dikonsumsi kepada teman.

3. Repurchase intention

Pembelian ulang yang dilakukan terhadap produk yang telah dikonsumsi.

Kepuasan dan loyalitas memiliki keterkaitan yang erat, karena tujuan utama perusahaan adalah menghasilkan kepuasan pelanggan yang bertujuan akhir mendapatkan pelanggan yang loyal. Tidak sepenuhnya kepuasan dapat menciptakan loyalitas, namun di sisi lain terdapat kebenaran meskipun kepuasan konsumen tidak tercapai, tetapi perusahaan tetap dapat menciptakan loyalitas konsumen. 
Berdasarkan uraian sebelumnya, agar tujuan penelitian dapat dicapai, maka diajukan 5 (lima) hipotesis penelitian yaitu: $(\mathrm{H} 1)$ Kualitas produk berpengaruh positif terhadap kepuasan pengguna, (H2) Kualitas layanan berpengaruh positif terhadap kepuasan pengguna, (H3) Kualitas produk berpengaruh terhadap loyalitas pengguna, $(\mathrm{H} 4)$ Kualitas layanan berpengaruh terhadap loyalitas pengguna, (H5) Kepuasan pengguna berpengaruh positif terhadap loyalitas pengguna. Keseluruhan rangkaian variabel, dimensi, dan hipotesis penelitian, terangkum dalam kerangka konsep Gambar 1 berikut.

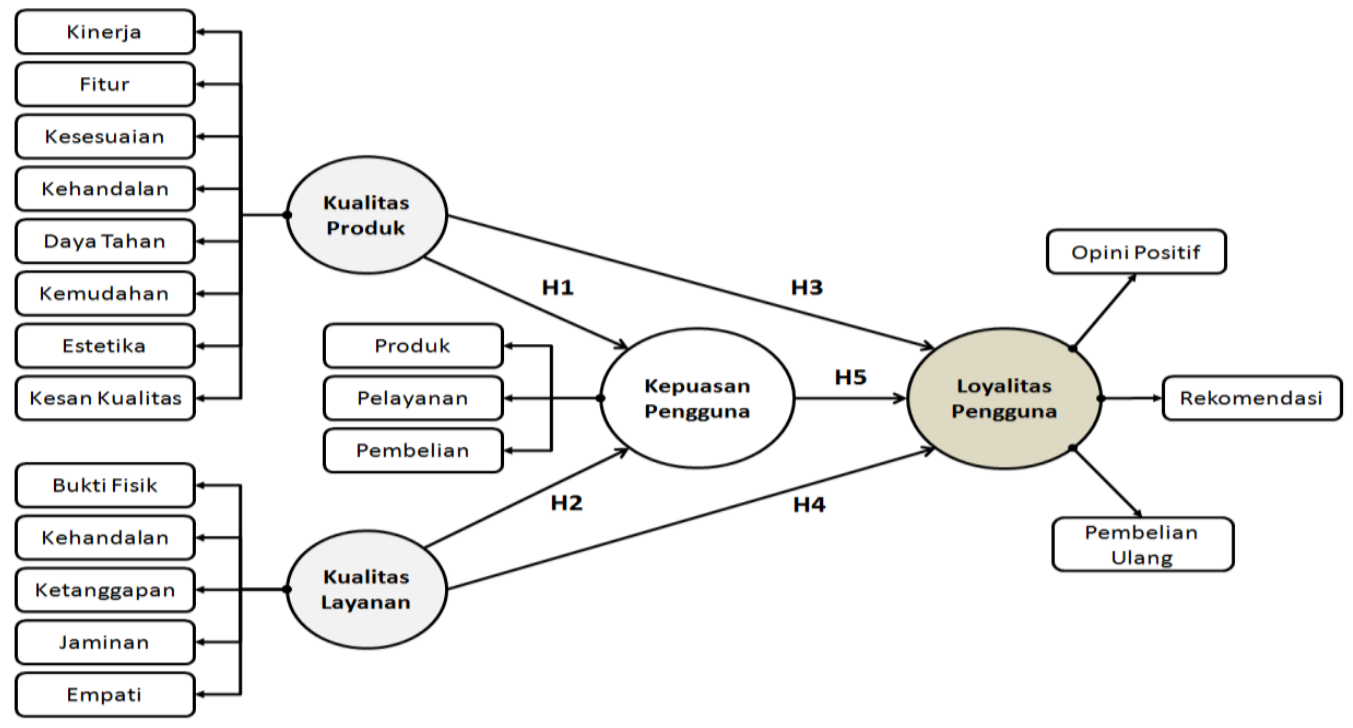

Gambar 1. Kerangka Konsep

Sumber: Mengadopsi Parasuraman (1994), Garvin (1987), Mowen and Minor (2002), Zeithaml and Bitner (1996)

\section{Metodologi}

Survei pendahuluan dilakukan untuk mengetahui persepsi masyarakat dalam hal pengguna KASM KBS yang berhasil ditemui, dengan cara mengamati keadaan sebenarnya di lokasi, disertai dengan pengujian data awal yang telah disiapkan penulis, dan proses wawancara. Persepsi awal pengguna mayoritas berpendapat bahwa unit KASM tersebut adalah produk/ barang milik PDAM Kota Surabaya, bukan layanan.

Jenis penelitian yang dilakukan yaitu penelitian survai. Sampel dalam penelitian ini melibatkan 100 pengunjung yang membeli tiket KBS sebagai responden. Teknik pengambilan sampel yang digunakan adalah accidental sampling. Pengumpulan data primer menggunakan kuesioner berisi pernyataan atas indikator-indikator sebagai manifestasi dari variabel-variabel dalam penelitian. Pengukuran indikator variabel menggunakan skala Likert, yaitu untuk persepsi "sangat setuju" diberi skor 5, "setuju” diberi skor 4, "netral" diberi skor 3, "tidak setuju" diberi skor 2, dan "sangat tidak setuju" diberi skor 1. Setiap item pernyataan akan melalui pengujian validitas dan reliabilitas dalam konstruk model penelitian. 


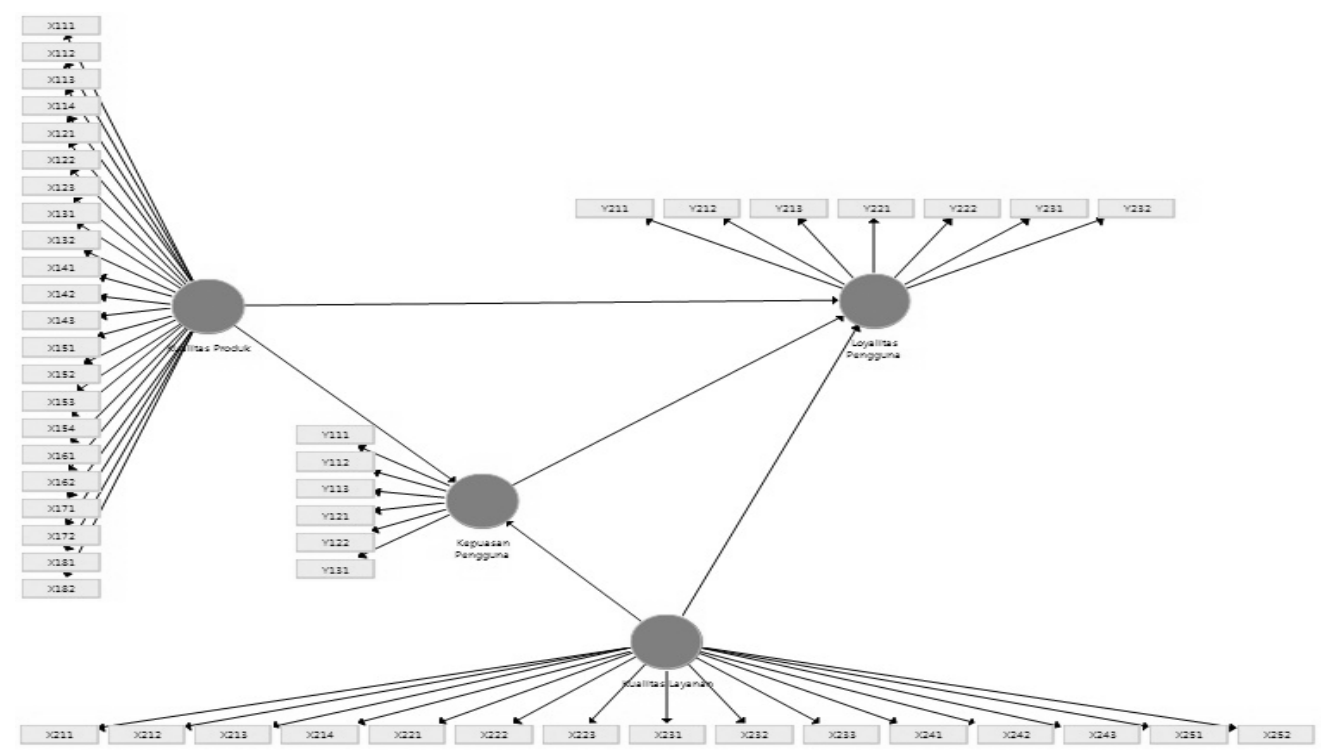

Gambar 2. Konstruk Model Penelitian

Sumber: Data diolah SEM-PLS

Analisis data dilakukan melalui pengukuran konstruk model dan hubungan antar variabel dengan teknik multivariat Structural Equation Modelling (SEM) - Partial Least Square (PLS), yang sering disebut juga sebagai generasi kedua dari analisis multivariate (Fornell, 1987). Konstruk model penelitian SEM-PLS, ditampilkan pada Gambar 2.

Variabel yang digunakan dalam penelitian ini, meliputi variabel bebas atau eksogen (X) yang terdiri dari kualitas produk (X1) dan kualitas pelayanan (X2), serta variabel terikat atau endogen $(\mathrm{Y})$ yang terdiri dari kepuasan pengguna $(\mathrm{Y} 1)$ dan loyalitas pengguna (Y2). Keseluruhannya dirumuskan dalam definisi operasional pada Tabel 1 berikut.

Tabel 1: Definisi Operasional Variabel Penelitian

\begin{tabular}{|c|c|c|c|}
\hline Variabel & Dimensi & Indikator & Simbol \\
\hline Eksogen & \multirow{5}{*}{$\begin{array}{l}\text { KINERJA } \\
(X 1.1)\end{array}$} & 1.Mengeluarkan air minum saat digunakan & $\mathrm{X} 1.1 .1$ \\
\hline Kualitas & & 2.Air minum keluar dengan tekanan yang & $\mathrm{X} 1.1 .2$ \\
\hline Produk (X1) & & cukup & \\
\hline (Garvin, 1987) & & $\begin{array}{l}\text { 3.Air minum keluar dengan kemiringan } \\
\text { yang sesuai }\end{array}$ & X1.1.3 \\
\hline \multirow{4}{*}{$\begin{array}{l}\text { dan hasil } \\
\text { survey } \\
\text { pendahuluan }\end{array}$} & & $\begin{array}{l}\text { 4.KASM bekerja sesuai petunjuk } \\
\text { penggunaan }\end{array}$ & X1.1.4 \\
\hline & \multirow{3}{*}{$\begin{array}{l}\text { FITUR } \\
(\mathrm{X} 1.2)\end{array}$} & $\begin{array}{l}\text { 1.Memiliki pilihan ketinggian keran air } \\
\text { minum sesuai postur pengguna }\end{array}$ & $\mathrm{X} 1.2 .1$ \\
\hline & & 2.Memiliki penunjuk indikator kerja/ operasi & $\mathrm{X} 1.2 .2$ \\
\hline & & 3.Memiliki atap pelindung & $\mathrm{X} 1.2 .3$ \\
\hline
\end{tabular}




\begin{tabular}{|c|c|c|c|}
\hline & \multirow{2}{*}{$\begin{array}{l}\text { KESESUAIAN } \\
(\mathrm{X} 1.3)\end{array}$} & $\begin{array}{l}\text { 1.Menghasilkan air minum yang tidak } \\
\text { berasa, berwarna, dan berbau }\end{array}$ & $\mathrm{X} 1.3 .1$ \\
\hline & & $\begin{array}{l}\text { 2.Menggunakan teknologi pemrosesan air } \\
\text { minum berkualitas tinggi }\end{array}$ & $\mathrm{X} 1.3 .2$ \\
\hline & \multirow{3}{*}{$\begin{array}{l}\text { KEHANDALAN } \\
(\mathrm{X} 1.4)\end{array}$} & $\begin{array}{l}\text { 1.Keran selalu mengeluarkan air minum } \\
\text { setiap saat digunakan (tidak macet) }\end{array}$ & $\mathrm{X} 1.4 .1$ \\
\hline & & $\begin{array}{l}\text { 2.Basin/ cawan dapat menampung dan } \\
\text { mengalirkan air yang tumpah dengan baik }\end{array}$ & $\mathrm{X} 1.4 .2$ \\
\hline & & $\begin{array}{l}\text { 3.Atap KASM mampu melindungi } \\
\text { pengguna }\end{array}$ & $\mathrm{X} 1.4 .3$ \\
\hline & \multirow{4}{*}{$\begin{array}{l}\text { DAYA TAHAN } \\
(\mathrm{X} 1.5)\end{array}$} & $\begin{array}{l}\text { 1.Kran air minum bermaterial stainless } \\
\text { steel }\end{array}$ & $\mathrm{X} 1.5 .1$ \\
\hline & & 2.Keran air minum tidak rusak & $\mathrm{X} 1.5 .2$ \\
\hline & & 3.Konstruksi unit KASM kuat dan kokoh & X1.5.3 \\
\hline & & $\begin{array}{l}\text { 4.Unit KASM tidak pernah berhenti } \\
\text { beroperasi }\end{array}$ & $\mathrm{X} 1.5 .4$ \\
\hline & \multirow{2}{*}{$\begin{array}{l}\text { KEMUDAHAN } \\
(\mathrm{X} 1.6)\end{array}$} & 1.KASM mudah digunakan & $\mathrm{X} 1.6 .1$ \\
\hline & & 2.KASM mudah diperbaiki jika bermasalah & $\mathrm{X} 1.6 .2$ \\
\hline & \multirow{2}{*}{$\begin{array}{l}\text { KEINDAHAN } \\
(\mathrm{X} 1.7)\end{array}$} & 3.KASM memiliki bentuk unik dan menarik & $\mathrm{X} 1.7 .1$ \\
\hline & & 4.Berpenampilan bersih dan higienis & $\mathrm{X} 1.7 .2$ \\
\hline & \multirow{2}{*}{$\begin{array}{l}\text { KESAN } \\
\text { KUALITAS } \\
(\mathrm{X} 1.8)\end{array}$} & $\begin{array}{l}\text { 1.Bermanfaat dan menunjang kegiatan di } \\
\text { lokasi }\end{array}$ & $\mathrm{X} 1.8 .1$ \\
\hline & & $\begin{array}{l}\text { 2.KASM meningkatkan citra PDAM Surya } \\
\text { Sembada }\end{array}$ & $\mathrm{X} 1.8 .2$ \\
\hline Variabel & Dimensi & Indikator & Simbol \\
\hline \multirow{4}{*}{$\begin{array}{l}\text { Eksogen } \\
\text { Kualitas } \\
\text { Layanan (X2) }\end{array}$} & \multirow{4}{*}{$\begin{array}{l}\text { BUKTI } \\
(\mathrm{X} 2.1)\end{array}$} & 1.KASM terjaga kebersihannya & $\mathrm{X} 2.1 .1$ \\
\hline & & $\begin{array}{l}\text { 2.KASM memiliki petunjuk cara } \\
\text { penggunaan }\end{array}$ & $X 2.1 .2$ \\
\hline & & $\begin{array}{l}\text { 3.KASM memiliki informasi kualitas air } \\
\text { minum }\end{array}$ & X2.1.3 \\
\hline & & 4.Terdapat petunjuk lokasi KASM di KBS & $\mathrm{X} 2.1 .4$ \\
\hline \multirow{3}{*}{$\begin{array}{l}\text { dan hasil } \\
\text { survey } \\
\text { pendahuluan }\end{array}$} & \multirow{3}{*}{$\begin{array}{l}\text { KEHANDALAN } \\
(\mathrm{X} 2.2)\end{array}$} & $\begin{array}{l}\text { 1.Air minum KASM selalu tersedia setiap } \\
\text { saat }\end{array}$ & $X 2.2 .1$ \\
\hline & & 2.KASM tidak mengalami kebocoran air & $\mathrm{X} 2.2 .2$ \\
\hline & & $\begin{array}{l}\text { 3.Tersedia petugas yang tepat dalam } \\
\text { pelayanan }\end{array}$ & X2.2.3 \\
\hline
\end{tabular}




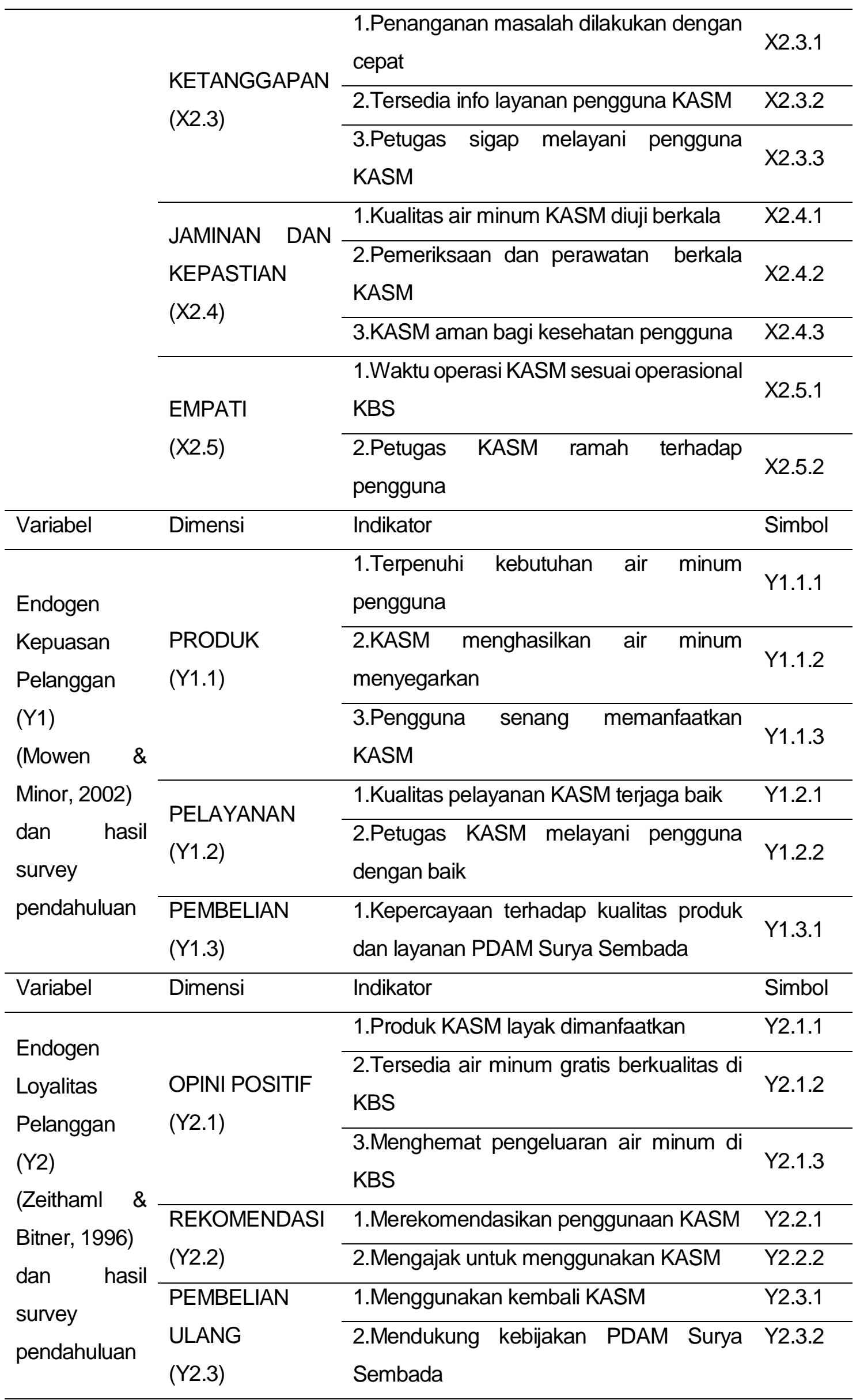


Data primer diolah menggunakan metode SEM-PLS untuk menganalisa hubungan dan pengaruh antara variabel kualitas produk dan kualitas layanan terhadap kepuasan dan loyalitas pengguna, dengan tahapan meliputi:

1. Pengolahan data menggunakan software Smart PLS

2. Desain outer model

3. Desain inner model

4. Analisa hasil outer model, yang terdiri dari convergent validity, discriminant validity, AVE, dan composite reliability

5. Analisa hasil inner model (R-Square)

\section{Hasil dan Pembahasan}

Data yang telah dimasukkan ke dalam konstruk model pada SmartPLS selanjutnya dikalkulasi (running) untuk mengetahui validitas dan realibilitasnya. Proses ini dapat dilakukan berulang kali hingga hasil nilai loading factor dari seluruh indikator sudah berada di atas syarat validitas sebesar 0,70 . Sedangkan indikator yang memiliki nilai loading factor di bawah 0,70 harus dihilangkan agar validitas dan reliabilitas dari model ini dapat ditingkatkan. Hasil kalkulasi SmartPLS yang telah memenuhi syarat validitas dan realibilitas sebagaimana tampak pada Gambar 3 berikut.

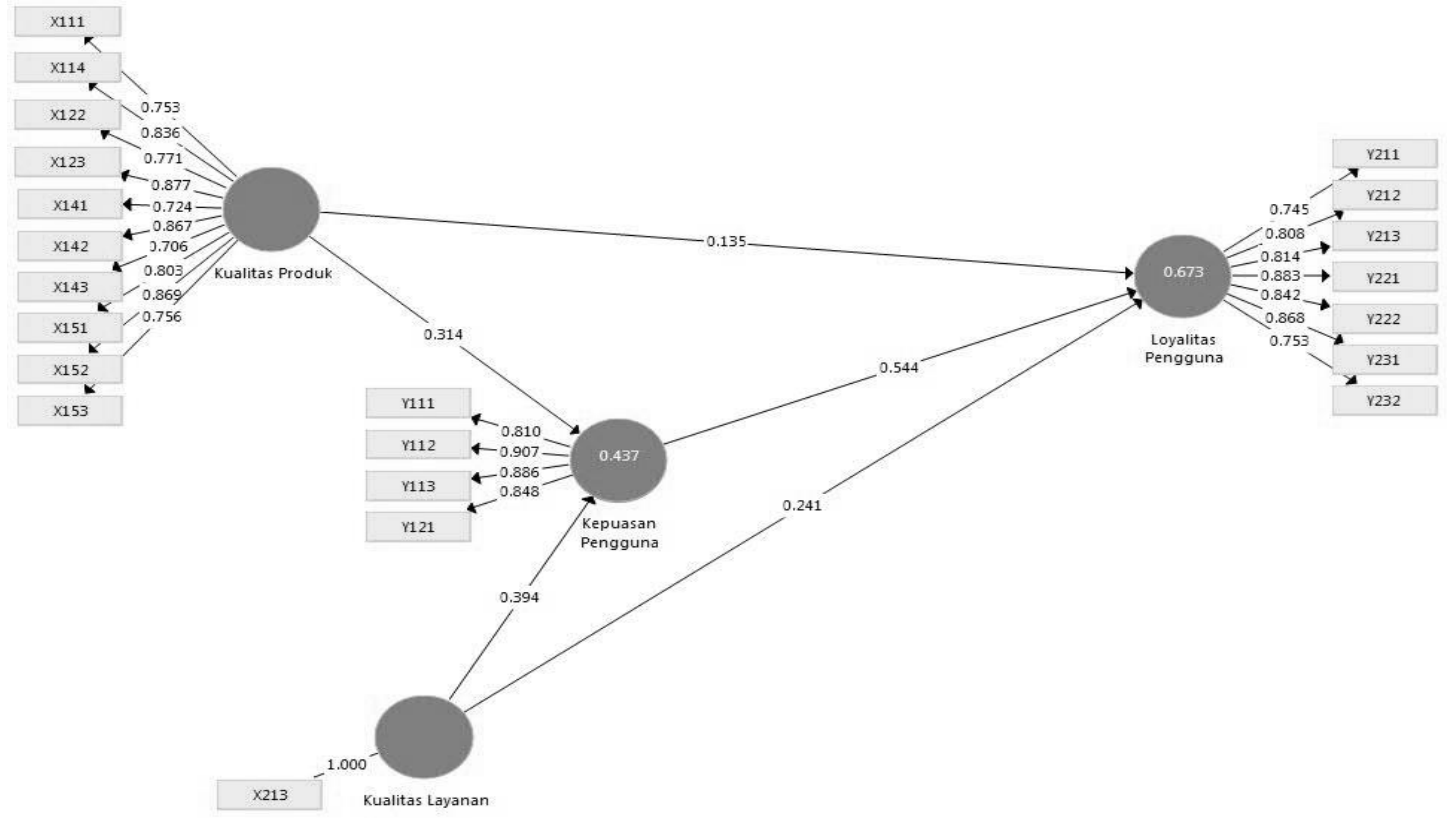

Gambar 3. Hasil Akhir Kalkulasi SmartPLS

Sumber: Data diolah SEM-PLS

Berdasarkan hasil eksekusi SmartPLS tahap akhir, seluruh indikator telah memiliki nilai loading factor di atas syarat validitas sebesar 0,70 , sehingga sudah memenuhi syarat pertama validasi evaluasi model. Terpenuhinya syarat pertama berdampak terhadap nilai 
AVE variabel laten di mana seluruhnya sudah memiliki nilai di atas 0,50 . Seluruh variabel juga sudah memenuhi syarat realibilitas dengan nilai di atas 0,70 , sehingga telah memenuhi syarat ke dua validasi model, dan siap untuk dilanjutkan ke tahap penilaian outer model. Kriteria evaluasi model dalam penilaian outer model menurut Ghozali (2015) sebagaimana resume dalam Tabel 2 berikut.

Tabel 2: Kriteria evaluasi model

\begin{tabular}{ll}
\hline \multicolumn{1}{c}{ Kriteria Evaluasi Model } & \multicolumn{1}{c}{ Penjelasan } \\
\hline Convergent Validity (Loading & Nilai loading factor harus di atas 0,70 untuk penelitian \\
Factor) & konfirmatori. Nilai loading factor $>0,60$ untuk \\
& penelitian eksploratori \\
\hline Composite Reliability & Nilainya $>0,70$ untuk penelitian konfirmatori \\
& Nilainya $0,60-0,70$ masih dapat diterima untuk \\
& penelitian eksploratori. \\
\hline
\end{tabular}

Average Variance Extracted Nilai AVE $>0,50$

(AVE)

\begin{tabular}{ll}
\hline Discriminant Validity & Nilai akar kuadrat dari AVE harus lebih besar daripada \\
& nilai korelasi antar variabel laten
\end{tabular}

Hipotesis diuji berdasarkan nilai koefisien jalur (path coefficient), sehingga diketahui signifikansi pengaruh antar konstruk, dengan melihat nilai koefisien parameter dan nilai tstatistik (t-hitung). Pengujian dilakukan 2 (dua) arah, dengan limitasi untuk menolak maupun menerima hipotesis yang diajukan, menggunakan nilai a sebesar $5 \%$, dan T-tabel sebesar 1,96. Jika nilai T-statistik lebih dari 1,96, maka hipotesis yang diajukan dapat diterima, namun jika nilai T-statistik kurang dari 1,96 maka hipotesis akan ditolak. Hasil kalkulasi path coefficient, sebagaimana dalam Gambar 4 berikut.

\begin{tabular}{|c|c|c|c|}
\hline \multicolumn{4}{|l|}{ Path Coefficients } \\
\hline \multicolumn{4}{|l|}{ Mean, STDEV, T-... } \\
\hline & Original Sample (O) & Sample Mean (M) & T Statistics (|O/STDEV|) \\
\hline Kepuasan Pengguna -> Loyalitas Pengguna & 0.544 & 0.545 & 6.700 \\
\hline Kualitas Layanan -> Kepuasan Pengguna & 0.394 & 0.383 & 3.235 \\
\hline Kualitas Layanan -> Loyalitas Pengguna & 0.241 & 0.236 & 2.778 \\
\hline Kualitas Produk -> Kepuasan Pengguna & 0.314 & 0.332 & 2.431 \\
\hline Kualitas Produk -> Loyalitas Pengguna & 0.135 & 0.144 & 1.581 \\
\hline
\end{tabular}

Gambar 4. Hasil Analisa Jalur Kalkulasi SmartPLS

Sumber: Data diolah SEM-PLS

Berdasarkan Gambar 4 menunjukkan bahwa variabel kualitas produk berpengaruh terhadap kepuasan pengguna $(0,314, \mathrm{~T}$-statistik $=2,431>$ T-tabel 1,96$)$, namun tidak 
berpengaruh langsung terhadap loyalitas pengguna $(0,135$, T-statistik 1,581 < T-tabel 1,96). Variabel kualitas layanan berpengaruh terhadap kepuasan pengguna $(0,394$, T-statistik 3,235 > T-tabel 1,96) dan berpengaruh langsung terhadap loyalitas pengguna $(0,241, T$ statistik 2,778 > T-tabel 1,96). Variabel kepuasan pengguna berpengaruh langsung terhadap loyalitas pengguna $(0,544$, T-statistik 6,700 > T-tabel 1,96). Hasil ini sekaligus menunjukkan hipotesis $3(\mathrm{H} 3)$ ditolak, karena dalam penelitian ini diperoleh bahwa kualitas produk memiliki dampak positif namun tidak berpengaruh langsung terhadap loyalitas pengguna. Analisa inner model R-Square merupakan uji goodness-fit atas model, sebagaimana dalam Gambar 5 berikut.

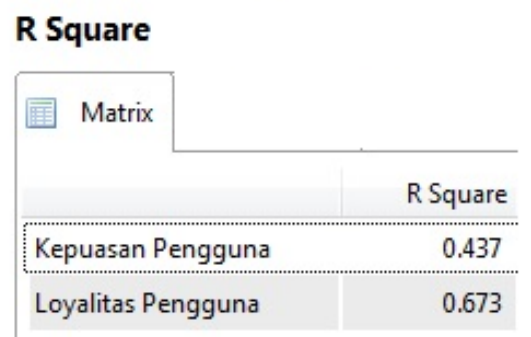

Gambar 5. Hasil R-Square Kalkulasi SmartPLS

Sumber: Data diolah SEM-PLS

Berdasarkan Gambar 5, variabel kepuasan pengguna dapat dijelaskan oleh variabel kualitas produk dan kualitas layanan sebesar 43,7\%, sedangkan 56,3\% dijelaskan oleh faktor lain. Selanjutnya variabel loyalitas pengguna dapat dijelaskan oleh variabel kualitas produk dan kualitas layanan sebesar $67,3 \%$, sedangkan $32,7 \%$ dijelaskan oleh faktor lain.

\section{Kesimpulan}

Berdasarkan hasil penelitian dan pembahasan, dapat disimpulkan beberapa poin sebagai berikut: (1) Hasil kalkulasi dengan SmartPLS terhadap hubungan antar variabel berdasarkan analisa path coefficients menunjukkan bahwa (a) Kualitas produk berpengaruh langsung dan signifikan terhadap kepuasan pengguna. Meskipun memiliki dampak positif tapi kualitas produk tidak memiliki pengaruh langsung terhadap loyalitas pengguna KASM KBS, (b) Kualitas layanan berpengaruh langsung dan signifikan terhadap kepuasan pengguna maupun terhadap loyalitas pengguna KASM KBS, dan (c) Kepuasan pengguna berpengaruh langsung dan signifikan terhadap loyalitas pengguna KASM KBS (2) Hipotesa 3 tidak terbukti dalam penelitian ini, menjadi konfirmatory bahwa kualitas produk memang bukan menjadi faktor pengaruh bagi loyalitas pengguna. Mengingat kualitas produk menjadi faktor yang berpengaruh terhadap kepuasan pengguna, maka sangat penting untuk menghasilkan kualitas produk yang sesuai ekspektasi pengguna, sehingga mampu menghasilkan kepuasan pengguna yang mendorong tumbuhnya loyalitas pengguna. 


\section{Saran}

Beberapa saran yang dapat dilakukan untuk penelitian di masa yang akan datang: (1) Objek penelitian dapat dikembangkan ke KASM lainnya, khususnya yang telah terpasang di ruang publik yang menjadi landmark maupun icon kota Surabaya lainnya, seperti Taman Bungkul, dll yang memiliki karakteristik berbeda (2) Penelitian selanjutnya dapat dilakukan dengan model penelitian yang memiliki dasar pendekatan berbeda, sehingga berpotensi memunculkan hasil penelitian yang bervariasi dan mungkin lebih relevan dengan kondisi aktual.

Konsekuensi manajerial bagi PDAM Surya Sembada Kota Surabaya terhadap layanan KASM berdasarkan penelitian ini, antara lain: (1) Optimalisasi sarana pesan broadcast eksisting, sebagai sarana penyebarluasan informasi dan pemasaran KASM (2) Meningkatkan konsistensi pelayanan melalui perbaikan data perawatan sebagai rujukan tindakan predictive maintenance instalasi KASM (3) Meningkatkan kesadaran masyarakat terhadap air minum berkualitas, melalui perbaikan informasi kualitas air produk KASM sebagai jaminan tingkat kepercayaan pengguna (4) Melakukan inovasi berkelanjutan terhadap produk instalasi KASM, dengan prioritas awal adalah desain atap pelindung dan tampilan informasi data kualitas air minum.

\section{Daftar Referensi}

Dinkominfo. 2014, Juli 7. kominfo.jatimprov. Diambil kembali dari http://kominfo.jatimprov.go.id/read/umum/40458 Diakses 7 April 2016

Fornell, C.1987. A Second Generation of Multivariate Analysis: Classification of Methods and Implications for Marketing Research. Dalam M. J. Houston, Review of Marketing (hal. 407-450). Chicago: American Marketing Association.

Garvin, D. A. 1987 Competing on the Eight Dimensions of Quality. Cambridge: Harvard Business Review.

Ghozali, I. 2014 Structural Equation Modeling Metode Alternatif dengan Partial Least Square (PLS) dilengkapi Software Smartpls 3.0 XIstat 2014 dan WarpPLS 4.0. Semarang: Badan Penerbit Universitas Diponegoro.

Ghozali, I., \& Latan, H. 2015. Partial Least Squares Konsep, Konsep, Teknik Dan Aplikasi Menggunakan Program SmartPLS 3.0 (2 ed.). Semarang: Badan Penerbit Universitas Diponegoro.

Kotler, P.2000. The Determinant of Perceived Service Quality and its Realtionship with Satisfactory. Service Marketing , 217-229.

Kotler, P., \& Keller, K. L. 2010. Marketing Management, 13th Edition. New Jersey: Pearson Education, Inc.

Meirovich, G., \& Bahnan, N.2008. Relationship between the components of product/ service. Journal of Industrial Engineering and Management , 186-208.

Mowen, J. C., \& Minor, M. 2002. Perilaku Konsumen (5th ed., Vol. I). (L. Salim, Penerj.) Jakarta: Erlangga. 
Parasuraman, A. Z. 1985. A Conceptual Model of Service Quality and Its Implication for Future Research. Journal of Marketing , 41-50.

Parasuraman, A. Z.1994. Reassessment of Expectation as A Comparison Standard in Measuring Service Quality : Implication for Further Research. Journal of Marketing , 111124.

Tjiptono, F., \& Chandra, G. 2008. Service Management: Mewujudkan Layanan Prima. Yogyakarta: Penerbit Andi.

Wiriya, S. 1996. Air Dalam Kehidupan dan Lingkungan yang Sehat. Bandung: Alumni.

Zeithaml, V., \& Bitner, M.1996. Service Marketing, International Edition. North America: McGraw-Hill Inc. 